\title{
Snake charming and the exploitation of snakes in Morocco
}

\author{
Juan M. Pleguezuelos, Mónica Feriche, José C. Brito and Soumía Fahd
}

\begin{abstract}
Traditional activities that potentially threaten biodiversity represent a challenge to conservationists as they try to reconcile the cultural dimensions of such activities. Quantifying the impact of traditional activities on biodiversity is always helpful for decision making in conservation. In the case of snake charming in Morocco, the practice was introduced there 500 years ago by the religious order the Aissawas, and is now an attraction in the country's growing tourism industry. As a consequence wild snake populations may be threatened by overexploitation. The focal species for snake charming, the Egyptian cobra Naja haje, is undergoing both range and population declines. We estimated the level of exploitation of snakes based on field surveys and questionnaires administered to Aissawas during 20032014, and compared our results with those of a study conducted 25 years previously. Aissawas use four venomous and four non-venomous species for snake charming and we estimate they harvest a minimum of 4,500 individuals annually, mostly venomous snakes. For exhibition purposes they selectively remove the largest specimens from the wild (i.e. those that could have the highest reproductive output). Compared to the previous data, we detected (1) a reduction in the number of species collected, (2) an increased distance to collecting fields, and (3) an increase in the market price for snakes, after correction for accumulated inflation, signifying a higher demand for these animals.
\end{abstract}

Keywords Aissawas, cobra, Morocco, Naja haje, Sahara, snake charming, tourism, unsustainable use

The supplementary material for this article can be found at https://doi.org/10.1017/So030605316000910

\section{Introduction}

Tnteractions between people and wildlife have long had an impact on biodiversity. Prehistoric and primitive societies used animals and their derivatives mainly as food but

Juan M. Pleguezuelos (Corresponding author) and Mónica Feriche Department of Zoology, University of Granada, E-18071 Granada, Spain

E-mail juanple@ugr.es

José C. BRITo Centro de Investigação em Biodiversidade e Recursos Genéticos, University of Porto, Vairão, Portugal

Soumía FAHD Department of Biology, Faculty of Science, Abdelmalek Essaâdi University, Tétouan, Morocco

Received 4 May 2016. Revision requested 28 June 2016.

Accepted 3 August 2016. First published online 22 December 2016. also for clothing, tools, medicine and pets, as well as in magic and religious activities (review in Alves \& Rosa, 2013). Vertebrates, particularly reptiles, have frequently been used for traditional medicine. Alves et al. (2008) identified 165 reptile species (30 families, 104 genera) currently used in traditional folk medicine, $53 \%$ of which are included on the IUCN Red List (IUCN, 2016) and/or the CITES Appendices (CITES, 2016). Among the reptile species being used for medicine, $36 \%$ are snakes.

Snakes have always both fascinated and repelled people, and the reported use of snakes in magic and religious activities is global (Alves et al., 2008). The sacred role of snakes may be related to a traditional association with health and eternity in some cultures (Angeletti et al., 1992) and many species are under pressure from exploitation as a result (Alves et al., 2008). The impact of hunting and collecting on snake populations has rarely been studied and remains largely unreported (Gibbons et al., 2000; Klemens \& Thorbjarnarson, 1995), and declines in snake populations are not receiving the same level of attention as, for example, those in amphibians or marine turtles (Mullin \& Seigel, 2009). Negative effects resulting from exploitation of snake populations must first be assessed before appropriate conservation measures can be established for species of concern.

Healers and indigenous peoples have collected wildlife for centuries but in the past harvests were relatively sustainable and species survival was not threatened (Alvard et al., 1997). Recent socio-economic-induced changes in human populations, however, such as those related to tourism development, long considered a clean industry with limited or no negative environmental impacts, are now affecting biodiversity (van der Duim \& Caalders, 2002). One example of this is the population decline in snakes used in snake charming, a practice that began in Morocco c. 500 years ago when Sidi Mohammed Ben Aissa, an Andalusian sufi, founded the religious order known as the Aissawas in Meknes, central Morocco (Brunel, 1926).

The Aissawas were healers and custodians of knowledge about the local flora and fauna. They used snakes in traditional medicine and exhibitions in market places (souks) throughout the country, inspiring the use of snakes in spectacles to attract tourists. Snakes used in such spectacles suffer from high mortality; when they show obvious signs of ill health they are disposed of and replaced by freshly caught individuals (Highfield \& Bayley, 2007). In 2014 Morocco registered 10,300,000 foreign visitors (6.5\% more than during the previous year; Tourisme en Chiffres, 2016) and tourism 
accounted for $6.7 \%$ of the country's gross domestic product (the second highest contributor after agriculture). The country plans to double the annual number of visitors by 2020 (Ministère du Tourisme du Maroc, 2016). If this objective is achieved the Aissawas have the potential to increase their financial gain by performing their spectacles at more tourist sites during an extended tourist season, and the demand for snakes will increase.

Morocco has a species-rich reptilian fauna, including 27 snake species. In a 2010 national-level assessment of extinction risk of amphibians and reptiles, based on IUCN criteria, snakes accounted for a high number of threatened species (18.5\%), with the two species commonly used for snake charming, the Egyptian cobra Naja haje and the puff adder Bitis arietans, categorized as Vulnerable (Pleguezuelos et al., 2010). Despite the prevalence of snake charming in Morocco there is no quantitative information regarding its overall effect on the country's snake fauna, as is generally the case in the search for empirical evidence of the potential effects of human activity on the fauna of an area (Webb et al., 2002).

During 2003-2014 we interviewed snake charmers in tourist areas throughout the country, and snake hunters, a distinctive group of Aissawas, in southern Morocco. Based on the accumulated responses we estimated (1) the number of snake charmers, the various species used, and the number of individual snakes they exhibited annually; (2) the number of snake hunters, the localities in which they were active, and the number of individuals of each species they collected; and (3) market prices for the focal species, $N$. haje. Some natural history traits of snakes were compared between the individuals used by Aissawas and the individuals we found during field surveys in the harvesting regions, to investigate selection based on these traits by Aissawas. Some of these variables could be indicative of the effect of harvesting on snake populations. Harvesting often selects against traits that would normally be advantageous under natural conditions (e.g. larger body size; Sasaki et al., 2009).

Our study replicates research on snake charming in Morocco by the late José Antonio Valverde during 1989-1996 (Valverde, 1989-2000), thus facilitating a comparison of the impacts of snake charming on Moroccan snakes between the two study periods. It is difficult to monitor changes in snake populations over time because of their elusive behaviour (Seigel \& Mullin, 2009). As a proxy, we compared, between periods, the number of species harvested, the localities where snakes were harvested, and the monetary values of $N$. haje. We assumed commercialization of snake charming had a negative effect if only the most striking snake species were targeted for harvesting. With respect to possible differences in the geographical location of hunting grounds between the two periods, we reasoned that hunting activity could be considered sustainable only if snake hunters were able to collect sufficient numbers of snakes in the same area over the study period. Movement of hunting activity towards more remote regions in the Sahara desert, however, would suggest that snake hunting was having a negative impact on snake populations (see a similar interpretation for a mammal species in Milner-Gulland \& Clayton, 2002). Local market prices for exploited species can serve as a surrogate for species population density in the wild and as a measure of sustainability in harvesting (Albrechtsen et al., 2007). A gradual increase in a snake's market price through time, after correction for accumulated annual inflation, may be interpreted as a reflection of the increasing difficulty of harvesting in the wild, and as being consistent with resource depletion (Milner-Gulland \& Clayton, 2002).

\section{Methods}

\section{Snake charmers}

On six occasions during 2003-2014 (2003, $2007(\times 2), 2011$, 2012, 2014), in spring and autumn, we searched for Aissawas and snake charming activity in the main cities, souks and tourist resorts of Morocco. Aissawas are wary of outsiders (Brunel, 1926), and therefore interviews were conducted by a Moroccan member of our research group (SF), who speaks Arabic and Berber and was therefore better accepted by the Aissawas (Albuquerque et al., 2014). Interviews were administered using a standardized form, and included questions about snake provenance and price, number of individuals acquired per year, and knowledge regarding the presence of other practitioners nearby (Supplementary Material 1). The interviews were conducted in the interviewees' primary environment (Albuquerque et al., 2014), and interviews with contradictory responses were eliminated from the analysis. Since the 1940s Aissawas in Marrakech (the stronghold for snake charming) have been organized into five closed groups, each consisting, on average, of 14 members (range 12-17); because of the complex relationship among snake charmers within each group (authors, unpubl. data), data from individual snake charmers are not independent, and only one datum per group in Marrakech was considered.

\section{Snake hunters}

Traditionally all Aissawas hunted for snakes used in charming but now only some custodians of the traditional culture are snake hunters; others, including many newcomers, buy snakes directly from hunters. This division of responsibility provided us with a control factor for gauging the impact of snake charming. We compared the numbers of snakes reported by snake charmers and hunters for all species each year. We assumed that hunters harvested snakes for the snake charmers, and that this approach would accurately 


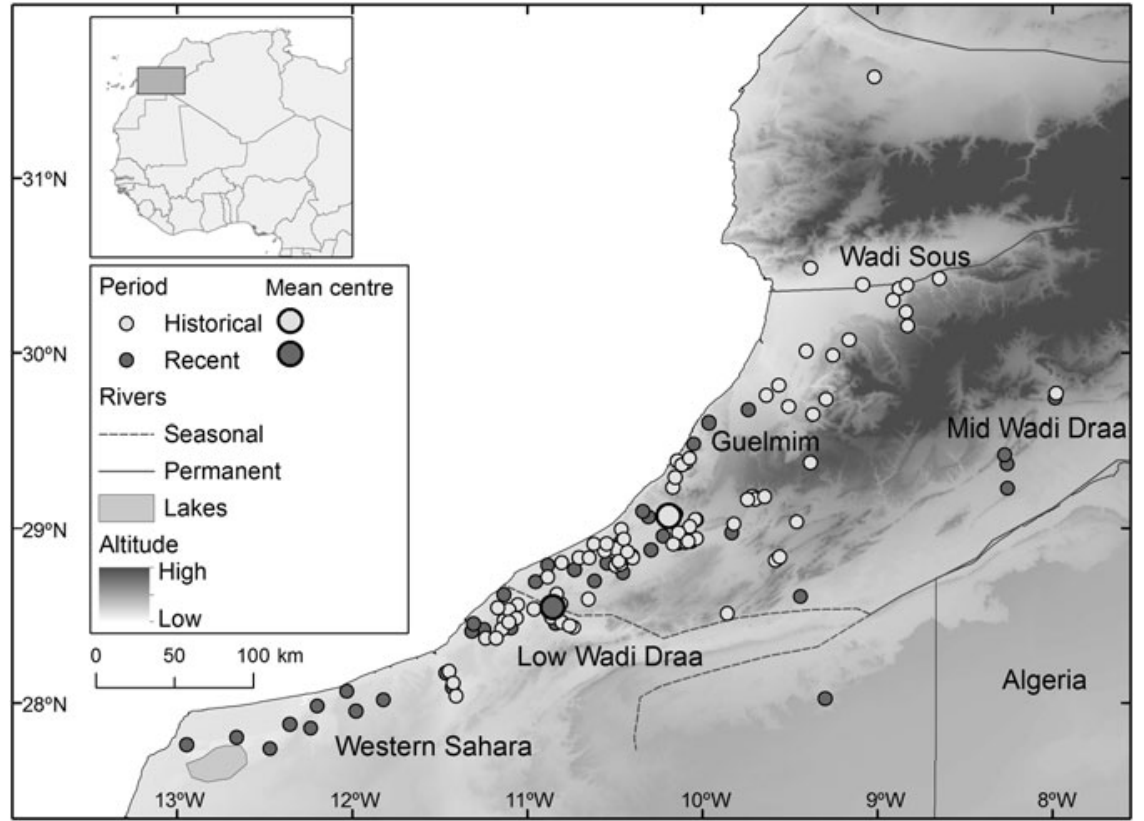

FIG. 1 Snake hunting sites in the Atlantic belt of south-western Morocco recorded during 1989-1996 (Valverde, 1989-2000) and 2003-2014 (this study). reflect the situation when the numbers compiled from hunters and charmers coincided. To gather data from snake hunters we targeted our efforts within the distribution range of $N$. haje, the focal species for snake charming, during the snake-hunting season (April-October). We recorded the location of each hunting site identified, using a global positioning system, and interviewed the hunters using a standardized form, which included questions about the species captured and the number of individuals of each species taken during each hunting trip (mean duration 15 days) and annually, and the price for individuals of each species (Supplementary Material 1).

In addition to administering the questionnaires, and when permitted to do so by the snake charmers and hunters, we also measured the snout-vent length (to the nearest $\mathrm{mm}$ ) and determined the sex from the tail shape of 173 specimens.

To compare natural history traits (body size, sex ratio) between specimens preferred by the Aissawas and those present in wild populations, occasionally during 2003-2012 we searched for snakes in the same hunting areas, during the same season as the Aissawas. We captured 59 individuals, which we identified, measured, sexed and released at capture sites. We compared data on body size by a Student's $t$ test if parametric and by the Mann-Whitney $U$ test if nonparametric, and sex ratio by $2 \times 2$ contingency tables.

\section{Comparison between periods}

During 1989-1996 J.A. Valverde recorded systematic information on snake charming in Morocco. We used his data on hunting sites $(n=133$, georeferenced using Google Earth; Supplementary Table $\mathrm{S}_{1}$ ), the species harvested, and the price of snakes used in spectacles (Valverde, 1989-2000). Geographical information system data for previous and recent hunting localities were evaluated for potential changes using the Mean Center tool in ArcView v. 9.o (ESRI, Redlands, USA). This spatial statistical tool uses projected data (in this case the georeferenced hunting localities) to measure distance accurately, and identifies the geographical centre of the data as a point constructed from the mean $x$ and $y$ values of the input features. We estimated the mean centre of the hunting grounds for both periods and measured the Euclidean distance between them (Fig. 1).

We combined data on prices of individuals during 19891996 with our data for 2003-2014, corrected for accumulated annual inflation in Morocco (World Bank, 2016), and regressed snake price on years, to examine any trend in the monetary value of snakes.

\section{Results}

We estimated there were a minimum of 86 snake charmers in Morocco during 2003-2014, 70 (81\%) located permanently in Marrakech and 16 elsewhere, mainly in western and southern cities (Tangier, Fez, Meknes, Safi, Agadir, Taroudant, Ouarzazate, Zagora, Tata, Tiznit, Sidi Ifni, Guelmime, Tan Tan), generally at tourist sites. Eight species (four venomous and four non-venomous) were used in their performances. Of these, four species (B. arietans, Hemorrhois hippocrepis, Malpolon monspessulanus, and $N$. haje) were commonly used; the other four were Cerastes cerastes, Daboia mauritanica, Psammophis schokari and Rhagerhis moilensis. During 1989-1996 Valverde recorded almost twice as many species being used: the same eight 
TABLE 1 For Morocco, the mean no. of snakes exploited annually per snake charmer interviewed $(n=9)$, estimated no. of snakes exploited annually by Aissawa snake charmers $(n=86)$, mean no. of snakes $( \pm S D)$ harvested annually per snake hunter interviewed $(n=12)$, estimated no. of snakes harvested annually by hunters $(n=36)$, and the difference in the numbers of snakes harvested by hunters and exploited for snake charming.

\begin{tabular}{|c|c|c|c|c|c|}
\hline Species & $\begin{array}{l}\text { Mean } \pm \text { SD exploited } \\
\text { per snake charmer } \\
(95 \% \mathrm{CI})\end{array}$ & $\begin{array}{l}\text { Estimated no. } \\
\text { exploited by snake } \\
\text { charmers }(95 \% \mathrm{CI})\end{array}$ & $\begin{array}{l}\text { Mean } \pm \text { SD harvested } \\
\text { per snake hunter } \\
(95 \% \mathrm{CI})\end{array}$ & $\begin{array}{l}\text { Estimated no. } \\
\text { harvested by snake } \\
\text { hunting }(95 \% \mathrm{CI})\end{array}$ & $\begin{array}{l}\text { Difference } \\
\text { between hunting \& } \\
\text { charming }(\%)\end{array}$ \\
\hline Bitis arietans & $\begin{array}{l}9.1 \pm 4.9 \\
(0-16)\end{array}$ & $\begin{array}{l}782.6 \\
(0-1,376)\end{array}$ & $\begin{array}{l}28.1 \pm 48.6 \\
(0-58.9)\end{array}$ & $\begin{array}{l}1,011.6 \\
(0-2,120.4)\end{array}$ & $\begin{array}{l}229.0 \\
(+29.2)\end{array}$ \\
\hline Cerastes cerastes & $\begin{array}{l}2.7 \pm 5.1 \\
(0-6.7)\end{array}$ & $\begin{array}{l}232.2 \\
(0-576.2)\end{array}$ & $\begin{array}{l}21.0 \pm 26.9 \\
(3.8-38.1)\end{array}$ & $\begin{array}{l}756.0 \\
(136.8-1,371.6)\end{array}$ & $\begin{array}{l}523.8 \\
(+225.5)\end{array}$ \\
\hline $\begin{array}{l}\text { Colubridae, } \\
\text { Lamprophiidae* }^{*}\end{array}$ & $\begin{array}{l}22.8 \pm 6.3 \\
(17.9-27.6)\end{array}$ & $\begin{array}{l}1,952.2 \\
(1,539.4-2,373.6)\end{array}$ & $\begin{array}{l}38.6 \pm 52.6 \\
(5.1-72.0)\end{array}$ & $\begin{array}{l}1,389.6 \\
(183.6-2,592.0)\end{array}$ & $\begin{array}{l}-562.6 \\
(-28.8)\end{array}$ \\
\hline $\begin{array}{l}\text { Daboia } \\
\text { mauritanica }\end{array}$ & $\begin{array}{l}1.7 \pm 2.7 \\
(0-3.7)\end{array}$ & $\begin{array}{l}146.2 \\
(0-318.2)\end{array}$ & $\begin{array}{l}14.2 \pm 19.8 \\
(1.6-26.7)\end{array}$ & $\begin{array}{l}518.4 \\
(57.6-961.2)\end{array}$ & $\begin{array}{l}372.2 \\
(+254.6)\end{array}$ \\
\hline Naja haje & $\begin{array}{l}3.6 \pm 1.1 \\
(2.8-4.5)\end{array}$ & $\begin{array}{l}309.6 \\
(240.8-387.0)\end{array}$ & $\begin{array}{l}20.2 \pm 26.0 \\
(3.7-36.8)\end{array}$ & $\begin{array}{l}727.2 \\
(133.2-1,324.8)\end{array}$ & $\begin{array}{l}417.6 \\
(+135.0)\end{array}$ \\
\hline All species & $\begin{array}{l}39.9 \pm 8.5 \\
(21.2-48.8)\end{array}$ & $\begin{array}{l}3,431.4 \\
(1,823.2-4,196.8)\end{array}$ & $\begin{array}{l}122.1 \pm 129.4 \\
(39.8-204.3)\end{array}$ & $\begin{array}{l}4,395.6 \\
(1,432.8-7,354.8)\end{array}$ & $\begin{array}{l}964.2 \\
(+28.1)\end{array}$ \\
\hline
\end{tabular}

${ }^{*}$ Colubridae includes Hemorrhois hippocrepis, and Lamprophiidae includes Malpolon monspessulanus, Psammophis schokari and Rhagerhis moilensis.

that we recorded plus Boaedon fuliginosus, Cerastes vipera, Hemorrhois algirus, Macroprotodon brevis, Spalerosophis diadema, Spalerosophis dolichospilus and Telescopus tripolitanus.

Snakes used for charming have a short life expectancy because of improper care and the high mortality of defanged individuals. When the snakes become unhealthy they are killed and skinned, and their meat is fed to other snakes. We completed nine independent and reliable questionnaires with snake charmers, all from male practitioners aged 25-70 years (four others were discarded because of contradictions in the responses). All snakes used by these snake charmers are derived from wild harvesting, with each charmer exploiting c. 40 individuals annually, and therefore we estimate that c. 3,500 snakes are exploited annually for snake charming (Table 1). Although there are large standard deviations for some species there is less variability for the species of greatest conservation concern, $N$. haje. During 2003-2014 each of the 36 snake hunters that we identified were actively searching for snakes in five regions (Medium Wadi Drâa, Wadi Sous Valley, Guelmim, Low Wadi Drâa, and occasionally the Tafilalt) collected c. 120 snakes annually; thus, in total $>4,300$ snakes were collected annually $(>28 \%$ more than were exhibited by snake charmers; Table 1).

We found no sex-ratio bias among the sample of snakes used by Aissawas (Table 2). However, individuals of six of the eight species in the possession of Aissawas were larger (two only marginally so) than those of the same species found by us in non-targeted sampling in the same collecting grounds (Table 2).

We recorded locations of 106 hunting sites (Supplementary Table S1) but were able to complete only 12 reliable interviews with snake hunters (only one was discarded). During 1989-1996 Aissawas collected snakes widely in the Middle Wadi Drâa Valley, Wadi Sous Valley and Guelmim, and less intensively in the southern Low Drâa Valley (Valverde, 1989-2000; Fig. 1). During 20032014 Aissawas rarely searched for snakes in the Wadi Sous Valley (in the northern portion of southern Morocco), focusing their efforts mostly in the Low Drâa. Preferred hunting grounds for snake hunters between 1989-1996 and 2003-2014 shifted to less accessible areas (c. $96 \mathrm{~km}$ southwest, Low Drâa), and further from Marrakech, the main snake-using area (Fig. 1).

The target species for snake charming in Morocco is $N$. haje, and as the least common wild species of those used by snake charmers it is also the most expensive species in the trade between hunters and charmers. Using our own data and those of Valverde (1989-200o) we estimated annual trends in the price of Egyptian cobras for 8 years during 1989-2014 and found that the price (corrected for inflation) increased substantially during this period (Fig. 2). During our survey period (2003-2014) the mean price was USD 42.7 (MAD 427; range MAD 100-1,200, $\mathrm{n}=22$ ).

\section{Discussion}

The number of snake charmers in Morocco is low compared with numbers in larger countries such as India, where snake charming is more widespread (Whitaker, 2006). In Morocco the activity is mostly restricted to key tourist areas, such as Marrakech. Practitioners may still be found in souks in the south of the country but not in the north, unlike 100 years ago (Hernández-Pacheco, 1914). In Marrakech the number of groups of practitioners (five) 
TABLE 2 Morphological and population data for snake species used in snake charming, compared with data from non-targeted sampling in the study areas in Morocco (Fig. 1).

\begin{tabular}{|c|c|c|c|c|c|c|}
\hline \multirow[b]{2}{*}{ Species } & \multicolumn{3}{|c|}{ Snake charming } & \multicolumn{2}{|c|}{ Non-targeted sampling } & \multirow[b]{2}{*}{ Comparisons ${ }^{\star}$} \\
\hline & $\begin{array}{l}\text { No. of } \\
\text { individuals }\end{array}$ & $\begin{array}{l}\text { Snout-vent length } \\
(\mathrm{mm}), \text { mean } \pm \text { SD }\end{array}$ & Sex ratio & $\begin{array}{l}\text { No. of } \\
\text { individuals }\end{array}$ & $\begin{array}{l}\text { Snout-vent length } \\
(\mathrm{mm}), \text { mean } \pm \text { SD }\end{array}$ & \\
\hline Bitis arietans & 20 & $851.0 \pm 177.7$ & $13 \mathrm{M}, 17 \mathrm{~F}$ & 5 & $544.0 \pm 326.5$ & $\begin{array}{l}Z=2.00, \mathbf{P}=\mathbf{0 . 0 4} \\
\chi^{2}=0.20, P=0.60\end{array}$ \\
\hline Cerastes cerastes & 11 & $502.4 \pm 81.3$ & $3 \mathrm{M}, 5 \mathrm{~F}$ & 7 & $425.7 \pm 144.3$ & $\begin{array}{l}Z=0.950, P=0.34 \\
\chi^{2}=0.28, P=0.59\end{array}$ \\
\hline $\begin{array}{l}\text { Daboia } \\
\text { mauritanica }\end{array}$ & 13 & $813.6 \pm 143.9$ & $5 \mathrm{M}, 9 \mathrm{~F}$ & 5 & $954.0 \pm 177.5$ & $\begin{array}{l}Z=-1.52, \mathrm{P}=0.12 \\
\chi^{2}=0.58, \mathrm{P}=0.44\end{array}$ \\
\hline $\begin{array}{l}\text { Hemorrhois } \\
\text { hippocrepis }\end{array}$ & 23 & $1,120.2 \pm 190.8$ & $11 \mathrm{M}, 9 \mathrm{H}$ & 17 & $932.2 \pm 308.6$ & $\begin{array}{l}t=2.37, \mathbf{P}=\mathbf{0 . 0 2} \\
\chi^{2}=0.22, \mathrm{P}=0.64\end{array}$ \\
\hline $\begin{array}{l}\text { Malpolon } \\
\quad \text { monspessulanus }\end{array}$ & 47 & $1,024.3 \pm 307.9$ & $32 \mathrm{M}, 18 \mathrm{~F}$ & 7 & $700.3 \pm 253.8$ & $\begin{array}{l}Z=2.51, \mathbf{P}=\mathbf{0 . 0 1} \\
\chi^{2}=2.00, P=0.15\end{array}$ \\
\hline Naja haje & 46 & $1,364 \pm 216$ & $18 \mathrm{M}, 22 \mathrm{~F}$ & 8 & $872 \pm 567$ & $\begin{array}{l}Z=2.27, \mathbf{P}=\mathbf{0 . 0 2} \\
\chi^{2}=0.20, P=0.65\end{array}$ \\
\hline $\begin{array}{l}\text { Psammophis } \\
\text { schokari }\end{array}$ & 5 & $716.8 \pm 98.9$ & $3 \mathrm{M}, 1 \mathrm{~F}$ & 8 & $580.0 \pm 136.2$ & $Z=1.90, \mathrm{P}=0.057$ \\
\hline Rhagerhis moilensis & 9 & $698.2 \pm 118.4$ & $6 \mathrm{M}, 2 \mathrm{~F}$ & 2 & $425.0 \pm 176.7$ & $Z=1.88, \mathrm{P}=0.06$ \\
\hline
\end{tabular}

${ }^{*}$ Frequencies of male and female individuals were tested against the null hypothesis of equal numbers $\left(2 \times 2\right.$ contingency table; $\chi^{2}$ distribution $)$, and means (Student's t-test or the Mann-Whitney U test, depending upon distribution normality). Bold font indicates significant differences.
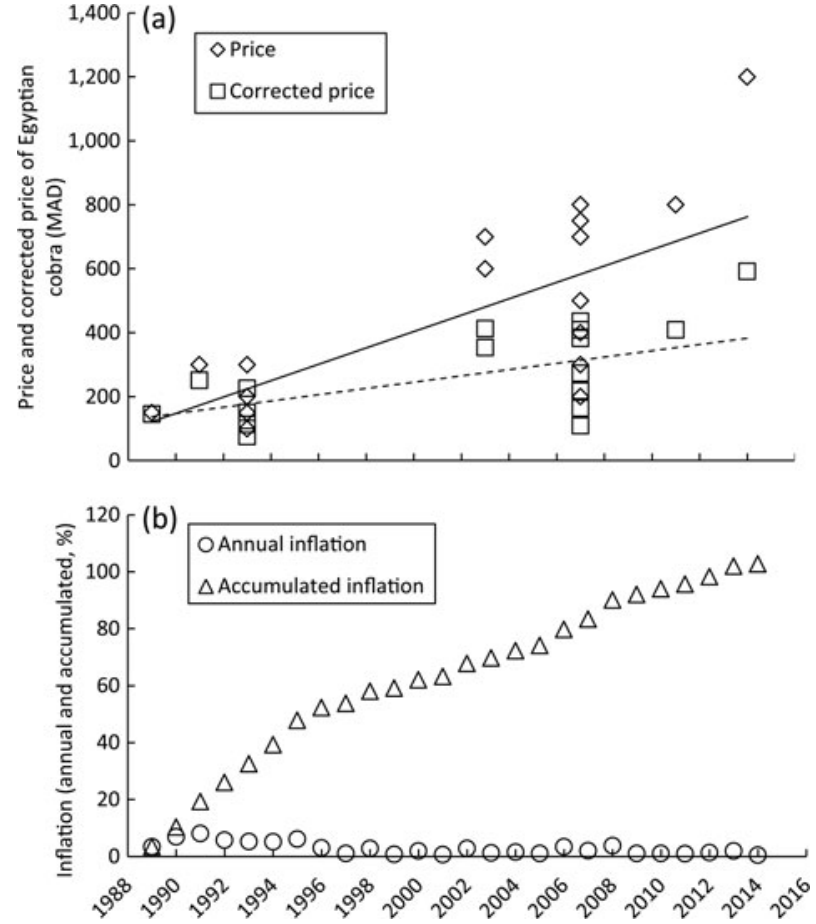

FIG. 2 Trends in (a) the price of the Egyptian cobra Naja haje $\left(y=-50,876.17+25.64^{*} x, r^{2}=0.495, P=0.0004\right)$, and the price of $N$. haje corrected for accumulated annual inflation in Morocco $\left(y=-19,392.21+9.81^{\star} x, r^{2}=0.320, P=0.007\right)$, and (b) inflation (annual and accumulated) in Morocco, during 1988-2014. (MAD $1=$ c. USD o.1).

has remained constant over the last three generations, but the intensity of performance has not. In former times snake charming was only one of the exhibitions of the
Aissawas (Meakin, 1905), and these exhibitions were limited to weekly souks, weddings and religious celebrations (Brunel, 1926); however, now it is possible to see snake charming in Marrakech's Jamaa el Fna year round, from dawn to dusk. Many of the snakes survive no more than a few weeks, and therefore there is an increased need for snake harvesting to supply these spectacles.

The number of species used in snake charming in Morocco during the last 20-25 years has decreased, with the Aissawas now using only the most striking and the most venomous species and, among non-venomous species, those that typically reach the largest sizes. There are no apparent declines in range or population density for snake species that are not currently exploited by the Aissawas (Pleguezuelos et al., 2010). We speculate that the reduction in the number of species exploited by the Aissawas signifies the loss of the traditional meaning of snake charming and indicates a trend towards commercialization of the activity, specializing in snakes that will attract tourists. The focal species for snake charming exhibit traits such as large body size (N. haje) and/or ambush foraging (B. arietans), and species with these characteristics are prone to extinction when subjected to stochastic events (Reed \& Shine, 2002), such as an increase in the hunting of snakes for charming. Both species are categorized as Vulnerable in Morocco (Pleguezuelos et al., 2010). The increase in construction of modern water cisterns throughout Morocco is a further threat to snakes, which become trapped in the cisterns and subsequently die (García-Cardenete et al., 2014).

We estimate that snake hunters in Morocco harvest almost 4,500 snakes per year, and that c. $75 \%$ of these are 
exploited by snake charmers. Although based on fewer valid interviews than we would prefer, we estimate that our sample includes $>10 \%$ of the country's snake charmers and one-third of its snake hunters. Interviewing members of the closed order of the Aissawas is difficult, even after reducing cultural interference (Albuquerque et al., 2014). Our data on snake charmers and snake hunters, resulting from two independent samples, corresponded and thus we infer that our estimates of exploitation levels for most snake species as a result of snake charming are reliable. More venomous snakes were hunted than exhibited, and more nonvenomous snakes were exhibited than were harvested by snake hunters. For venomous snakes we interpret the difference as having resulted from high mortality during transportation and captivity, from the illegal trade in snakes, and from the sale of snakes to the Moroccan Antivenin Centre in Rabat (authors, pers. obs.). For non-venomous snakes the difference is attributable to the occasional harvesting of snakes from areas surrounding spectacle sites by snake charmers themselves (authors, per. obs.).

Snake charmers used larger individuals in spectacles than those found in our non-targeted sampling in the wild. As snake charming relies on visual impact, hunters apparently select the largest, most striking individuals from the field. Smaller individuals are not actively sought, according to statements from snake hunters, and when captured serve as live food for larger captive snakes. The focus on larger snakes by hunters may have a significant impact on natural snake populations. Some harvested individuals of $N$. haje, M. monspessulanus and $H$. hippocrepis exceed the maximum prey size for snake predators in the study area (e.g. the short-toed eagle Circaetus gallicus, a specialist snake-eater; Gil \& Pleguezuelos, 2001). The Aissawas may therefore be effecting phenotypic selection on a portion of the snake population that normally avoids natural predation, potentially resulting in reduced population fitness (Sasaki et al., 2009). The largest snakes in natural populations are probably the best adapted and most productive of the breeding individuals, and continued removal of the largest females will eventually reduce the reproductive output of the entire population (Sasaki et al., 2009); for example, the practice of rattlesnake roundups in the central USA, where the largest individuals are usually selected, significantly affects the demography of the prairie rattlesnake Crotalus viridis (Fitch, 1998), and the collection of the largest local snakes for use in procession rituals around Cocullo, Italy, reportedly delayed snake reproduction (Filippi \& Luiselli, 2003).

Sex-biased snake harvesting has been observed elsewhere (Fitzgerald \& Painter, 2000; Webb et al., 2002) but we observed a balanced sex ratio among the snakes used by the Aissawa in snake charming spectacles. This finding, contrary to general statements made by snake hunters, suggests that they do not release pregnant females, which is another cause for concern regarding the conservation of wild snake populations (Fitch, 1998).
Snake hunting grounds in Morocco correspond closely to the range of $N$. haje, with most hunters operating in the south-west (Middle and Low Drâa, Guelmim), where records are concentrated. The southwards shift in hunting grounds between 1989-1996 and 2003-2014 suggests there has been a decline in snake populations in northern regions. Moreover, species hunted in small areas can rarely resist intensive harvesting (Fitzgerald et al., 2004), and although $N$. haje is distributed widely in southern Morocco, it occupies microhabitats with sufficient vegetation to sustain populations of its main prey, the fat sand rat Psammomys obesus, which in the Sahara desert occurs only in patches along wadis (temporary water courses). Snake hunters understand the spatial ecology of both species and search intensively for $N$. haje in these patches, where they are more accessible to hunters than if they occurred in open landscapes (Turner \& Corlett, 1996). Based on our experience we reject alternative reasons for sourcing snakes from further distances, such as improved transport, because snake hunters are economically poor and thus choose the least expensive means to acquire their materials.

Abundance also reflects the status of wildlife populations (Lawton, 1993). A general comment among older Aissawas is that within current hunting grounds for $N$. haje there are fewer snakes and more hunters than some decades ago. Snake hunters can identify the recent presence of another hunter (because of the excavated snake burrows), and avoid such areas. Displacement of snake harvesting grounds further to the south requires snake hunters to spend more time and resources in pursuit of their craft, with reduced facilities (e.g. transport, water availability) and limited opportunities to earn a living in regions such as the Lower Drâa and Western Sahara. This, in part, explains the increasing prices for $N$. haje in the trade between hunters and snake charmers between the two periods.

Unequivocally linking cause and effect for factors threatening biodiversity is difficult. However, our data support the hypothesis that $N$. haje has declined as a result of the hunting pressure exerted by snake charming, with evidence of reductions in the species' range and population. Given the active selection of the largest individuals, hunting pressure could also trigger a rapid and negative evolutionary response, as observed in overhunted populations of the Japanese mamushi Gloydius blomhoffii (Sasaki et al., 2009).

The cultural and traditional significance of snake charming in Morocco precludes a proposal to ban this activity completely. Forty years after a ban on snake charming was introduced in India snake charming continues, albeit as a clandestine activity (Whitaker, 2006). We understand that protecting traditional knowledge and culture is important, particularly within the context of globalization; such knowledge provides status for its custodians, who may otherwise have limited opportunity for employment. However, the threat to exploited snake populations will continue if the 
use of these snakes continues unregulated. Although snakes are currently protected in Morocco (Décret d'application de la loi 29-05, catégorie IV), the number of snakes harvested by snake hunters and used in spectacles by snake charmers is not restricted (Bergin \& Nijman, 2014). Uncontrolled exploitation of wildlife resources threatens both the species exploited and the human populations depending on them (Whitaker, 2006). However, there are possibilities for reconciling conservation and traditional cultures. Based on our baseline information about the negative effects of snake charming in Morocco, which are directly attributed to the Aissawas order, we recommend that the government (1) control the exploitation of snakes by issuing personal licences to snake charmers and hunters, (2) limit the number of snakes a snake charmer may acquire per year, and mark (by passive integrated transponder, controlled by the veterinary services of the Moroccan Administration) those of the most vulnerable species, (3) develop a captive-breeding and rearing programme for the most threatened species, $N$. haje, to support snake charming and antivenin laboratories and provide Aissawas with training on snake husbandry, (4) ban the exhibition of defanged snakes, (5) ban performances during extreme weather conditions, such as the early hours of low temperature during winter and the midday hours of excessive heat during summer, and (6) take advantage of other skills of the Aissawas, such as tracking snakes and other wildlife, their knowledge of medicinal plants, and their potential as conservation educators. These recommendations will be passed to the relevant authorities.

\section{Acknowledgements}

We dedicate this project to the late J.A. Valverde, who was the first to study this topic in Morocco, and we thank the librarians at the University of Salamanca for providing access to Valverde's field notebooks. We are deeply indebted to those snake hunters from whom we have learned so much, especially the old M'Barek Abaloul, and to all who aided us in our surveys. Xavier Santos and Stephen D. Busack provided useful comments on the article. JCB is supported by Fundação para a Ciência e Tecnologia (contract $\mathrm{IF} / 459 / 2013)$. This study was self-funded.

\section{Author contributions}

JMP designed the research, MF, JCB and SF focused on field surveys and data management, and all authors contributed to writing the article.

\section{References}

Albrechtsen, L., Macdonald, D.W., Johnson, P.J., Castelo, R. \& $\mathrm{FA}_{\mathrm{A}}$, J.E. (2007) Faunal loss from bushmeat hunting: empirical evidence and policy implications in Bioko Island. Environmental Science \& Policy, 10, 654-667.

Albuquerque, U.P., Lucena, R.F.P. \& Alencar, N.L. (2014) Methods and techniques used to collect ethnobiological data. In Methods and Techniques in Ethnobiology and Ethnoecology (eds U.P. Albuquerque, R.F.P. Lucena, L. Cunha \& R.R.N. Alves), pp. 15-37. Springer, New York, USA.

Alvard, M.S., Robinson, J.G., Redford, K.H. \& Kaplan, H. (1997) The sustainability of subsistence hunting in the Neotropics. Conservation Biology, 11, 977-982.

Alves, R.R.N. \& RosA, I.L. (2013) Animals in Traditional Folk Medicine. Springer, Heidelberg, Germany.

Alves, R.R.N., Vieira, W.L.S. \& Gomes-Santana, G. (2008) Reptiles used in traditional folk medicine: conservation implications. Biodiversity and Conservation, 17, 2037-2049.

Angeletti, L.R., Agrimi, U., French, D., Curia, C. \& Mariani-Costantini, R. (1992) Healing rituals and sacred serpents. The Lancet, 340, 223-225.

Bergin, D. \& Nijman, V. (2014) Illegal and open wildlife trade in Morocco's capital. Swara, July-September, 54-57.

Brunel, R. (1926) Essai sur la Confrérie Religieuse des Aîssâoûa au Maroc. Geuthner, Paris, France.

CITES (2016) The CITES Appendices. Http://www.cites.org/eng/app/ index.shtml [accessed 17 October 2016].

Filippi, E. \& Luiselli, L. (2003) Delayed reproduction in snakes subjected to human traditional rituals in central Italy. Vie et Milieu, $53,111-118$.

Fitch, H.S. (1998) The Sharon Springs roundup and praire rattlesnake demography. Transactions of the Kansas Academy of Sciences, 101, 101-113.

Fitzgerald, L.A. \& Painter, C.W. (2000) Rattlesnake commercialization: long-term trends, issues, and implications for conservation. Wildlife Society Bulletin, 28, 235-253.

Fitzgerald, L.A., Painter, C.W., Reuter, A. \& Hoover, C. (2004) Collection, Trade, and Regulation of Reptiles and Amphibians of the Chihuahuan Desert Ecoregion. TRAFFIC North America, Washington, DC, USA.

García-Cardenete, L., Pleguezuelos, J.M., Brito, J.C., Jiménez-Cazalla, F., Pérez-García, M.T. \& Santos, X. (2014) Water cisterns as death traps for amphibians and reptiles in arid environments. Environmental Conservation, 41, 341-349.

Gibbons, J.W., Scott, D.E., Ryan, T.J., Buhlmann, K.A., Tuberville, T.D., Metts, B.S. et al. (200o) The global decline of reptiles, déjà vu amphibians. BioScience, 50, 653-666.

Gíl, J.M. \& Pleguezuelos, J.M. (2001) Prey and prey-size selection by the short-toed eagle (Circaetus gallicus) during the breeding season in Granada (south-eastern Spain). Journal of Zoology, 255, 131-137.

Hernández-Pacheco, E. (1914) Yebala yel bajo Lucus. Real Sociedad Española de Historia Natural, Madrid, Spain.

Highfield, A.C. \& BAyley, J.R. (2007) Folklore, myth and exploitation of reptiles in Morocco and Tunisia. Http://www. tortoisetrust.org/articles/exploit.html [accessed 12 November 2015].

IUCN (2016) The IUCN Red List of Threatened Species v. 2016-2. Http://www.iucnredlist.org [accessed 17 October 2016].

Klemens, M.W. \& Thorbjarnarson, J.B. (1995) Reptiles as a food resource. Biodiversity and Conservation, 4, 281-298.

Lawton, J.H. (1993) Range, population abundance and conservation. Trends in Ecology \& Evolution, 8, 409-413.

Meakin, B. (1905) Life in Morocco and Glimpses Beyond. Chatto \& Windus, London, UK.

Milner-Gulland, E.J. \& Clayton, L. (2002) The trade in babirusas and wild pigs in North Sulawesi, Indonesia. Ecological Economics, $42,165-183$. 
Ministére du Tourisme du Maroc (2016) Engagement \& objectifs. Http://www.tourisme.gov.ma/fr/vision-2020/presentation/ engagement-objectifs [accessed 15 November 2016].

Mullin, S.J. \& Seigel, R.A. (2009) Snakes: Ecology and Conservation. Cornell University Press, Ithaca, USA.

Pleguezuelos, J.M., Brito, J.C., Fahd, S., Feriche, M., Mateo, J. A., Moreno-Rueda, G. et al. (2010) Setting conservation priorities for the Moroccan herpetofauna: the utility of regional red lists. Oryx 44, 501-508.

Reed, R.N. \& Shine, R. (2002) Lying in wait for extinction: ecological correlates of conservation status among Australian elapid snakes. Conservation Biology, 16, 451-461.

Sasaki, K., Fox, S.F. \& Duvall, D. (2009) Rapid evolution in the wild: changes in body size, life-history traits, and behavior in hunted populations of the Japanese mamushi snake. Conservation Biology, 23, 93-102.

Seigel, R.A. \& Mullin, S.J. (2009) Snake conservation, present and future. In Snakes: Ecology and Conservation (eds S.J. Mullin \& R. A. Seigel), pp. 281-290. Cornell University Press, Ithaca, USA.

TOURISME EN CHIFFres (2016) Http://www.tourisme.gov.ma/fr/tourismeen-chiffres [accessed 18 October 2016].

Turner, I.M. \& CorletT, R.T. (1996) The conservation value of small, isolated fragments of lowland tropical rain forest. Trends in Ecology \& Evolution, 11, 330-333.
Valverde, J.A. (1989-200o) Cuadernos de Campo. AUSA_JAV,10o/3. Archivos Universidad de Salamanca, Salamanca, Spain.

VAN DER DUim, R. \& CAAlders, J. (2002) Biodiversity and tourism: impacts and interventions. Annals of Tourism Research, 29, 743-761.

Weвв, J.K., Brook, B.W. \& Shine, R. (2002) Collectors endanger Australia's most threatened snake, the broad-headed snake Hoplocephalus bungaroides. Oryx, 36, 170-181.

Whit A Ker, R. (2006) Common Indian Snakes. Macmillan, New York, USA.

WORLD BANK (2016) Http://www.worldbank.org/en/country/ morocco [accessed 15 November 2016].

\section{Biographical sketches}

Over the last 16 years the authors have collaborated on projects on the ecology, phylogeography and conservation biology of western Mediterranean reptiles. They have extensive expertise in the distribution and ecology of the herpetofauna of the Maghreb, particularly of Mauritania and Morocco, having organized and participated in at least 40 scientific expeditions in these countries. Collaboratively the authors seek to investigate the threats to herpetofauna and improve the conservation of these species in Morocco. 